\title{
Seasonal variation of sound production in the Lusitanian toadfish Halobatrachus didactylus
}

\author{
M. C. P. Amorim*†, R. O. Vasconcelos*, J. F. Marques \\ AND F. AlmadA* $\S$ \\ *Unidade de Investigação em Eco-Etologia, I.S.P.A., Rua Jardim do Tabaco 34, 1149-041 \\ Lisboa, Portugal, $\$$ Universidade de Lisboa, Faculdade de Ciências, Instituto de \\ Oceanografia, Campo Grande, 1749-016 Lisboa, Portugal and §Unidade de Investigação \\ em Biodiversidade e Desenvolvimento, Universidade Lusófona de Humanidades e \\ Tecnologias, Campo Grande 376, 1749-024 Lisboa, Portugal
}

(Received 22 November 2005, Accepted 25 July 2006)

\begin{abstract}
Seasonal variation of sound production, which includes boatwhistles, grunts, croaks and double croaks, was studied in the Lusitanian toadfish Halobatrachus didactylus. Boatwhistles were emitted during the mating season in contrast with the other sound types, which were emitted all year round.

(C) 2006 The Authors

Journal compilation (C) 2006 The Fisheries Society of the British Isles
\end{abstract}

Key words: acoustic communication; mate attraction; nesting males; temperature; territorial establishment; vocal activity.

Pronounced seasonal patterns of sound production in mature fishes are typically related to reproductive activities. Male members of the toadfish family (Batrachoididae) defend nests in the breeding season, are polygynous, provide parental care and emit a long tonal boatwhistle advertisement call from their nest that is used in male-male competition and mate attraction (Gray \& Winn, 1961; Fish, 1972). In the species studied up to date (Bass \& McKibben, 2003; Amorim, 2006), both genders produce agonistic broadband pulsed sounds (grunts), but only males emit tonal mating sounds (boatwhistles or hums). These are produced by the extremely fast contraction of the intrinsic sonic muscles upon the swimbladder (Fine et al., 2001). The Lusitanian toadfish Halobatrachus didactylus (Bloch \& Schneider) (Batrachoididae) is an ubiquitous sound producer that lives along the coast of Portugal in estuarine murky waters (dos Santos et al., 2000). During the reproductive season that lasts from May to July in Portugal (Modesto \& Canário, 2003a), breeding Lusitanian toadfish males defend nests in shallow water and provide parental care to the eggs in the nest until the young are free-swimming (Brantley \& Bass, 1994;

$\dagger$ Author to whom correspondence should be addressed. Tel.: +351 218811700; fax: +351 218860954; email: amorim@ispa.pt 
dos Santos et al., 2000). Recordings made during the breeding season have shown that males of this species have an unusual large acoustic repertoire for fishes, which consists of four distinct sound types: boatwhistles, grunts, croaks and double croaks (dos Santos et al., 2000). Boatwhistles emitted by the Lusitanian toadfish are tonal sounds, $c .800 \mathrm{~ms}$ long, which start and end with a grunt-like portion. The fundamental frequency is $c .60 \mathrm{~Hz}$ and dominant frequencies are typically either the second or the fourth harmonic (pers. obs.) (Fig. 1). Grunts are short drumming sounds emitted in trains (typically eight grunts per grunt train) with dominant frequencies around $300 \mathrm{~Hz}$ (Fig. 1). Croaks are low frequency pulsed sounds emitted in isolation; they are longer and present higher dominant frequencies (around $650 \mathrm{~Hz}$ ) than individual grunts and, unlike double croaks, do not show amplitude or frequency modulation (dos Santos et al., 2000). In contrast, double croaks are made up of two croak-like elements that present both amplitude and frequency modulation, with typical durations of c. $90 \mathrm{~ms}$ (each) and dominant frequencies around $500 \mathrm{~Hz}$ (Fig. 1).

Little is known on the function of the different sound types and how sound emissions vary throughout the year. Dos Santos et al. (2000) have suggested, in analogy to other batrachoidids, that boatwhistles are mating signals whereas the other sound types are probably agonistic. If this is true, it would be predicted that boatwhistles should only be heard during the breeding season whereas the other sound types should be heard all year round, especially during territory establishment at the start of the breeding season. To test this prediction, seasonal variations of sound production were studied in this species. Several acoustic features of boatwhistles, grunts and double croaks were also measured and correlated with water temperature. These three sound types were the most frequent sound emissions registered in this study.

Recordings of the Lusitanian toadfish sounds were made from piers in two areas within the Tagus estuary, Portugal: Montijo $\left(38^{\circ} 42^{\prime} \mathrm{N} ; 8^{\circ} 58^{\prime} \mathrm{W}\right.$ ) and Barreiro (38 $\left.39^{\prime} \mathrm{N} ; 9^{\circ} 04^{\prime} \mathrm{W}\right)$. An average of five recording sessions (ranging from two to seven) lasting from 5 to 10 min were carried out approximately once a month from July 2001 to September 2002. Recording locations were at least $4 \mathrm{~m}$ apart. Water depth varied approximately between 0.8 and $4.0 \mathrm{~m}$, depending on tide. Sounds were registered with a High Tech 94 SSQ hydrophone (sensitivity of $-165 \mathrm{~dB}$ re $1 \mathrm{~V} / \mu \mathrm{Pa}$, flat frequency response up to 6 $\mathrm{kHz} \pm 1 \mathrm{~dB}$ ) and a Sony TCD-D8 DAT recorder. A thermometer was attached to the hydrophone to register water temperature. Sounds were digitized at $44 \mathrm{kHz}$ (16 bit resolution) and analysed with Raven 1.2 for Windows (Bioacoustics Research Program, Cornell Laboratory of Ornithology, Ithaca, NY, U.S.A.).

Sound production rate (number of sounds $\mathrm{min}^{-1}$ ) was determined for each recording session and sound type by listening to the recordings and simultaneously checking the spectrographic representation of the sounds. Only the sounds emitted by fish close to the hydrophone were counted (i.e. those that showed a clear representation both in the spectrogram and oscillogram). Because grunts are emitted in trains (dos Santos et al., 2000), the number of grunt trains was counted instead of single grunts. Sound emission rate was compared between recording dates with one-way ANOVAs. The square root transformation was applied to the data because group variances were proportional to the 

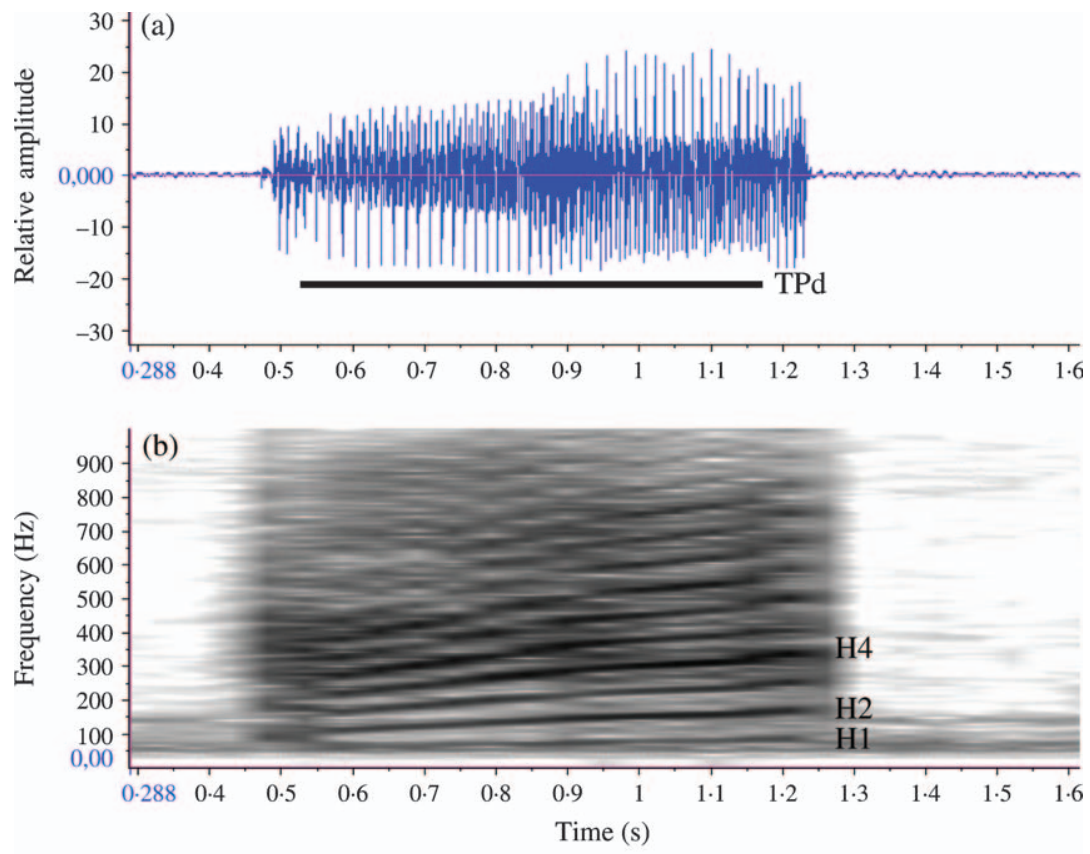

(c)

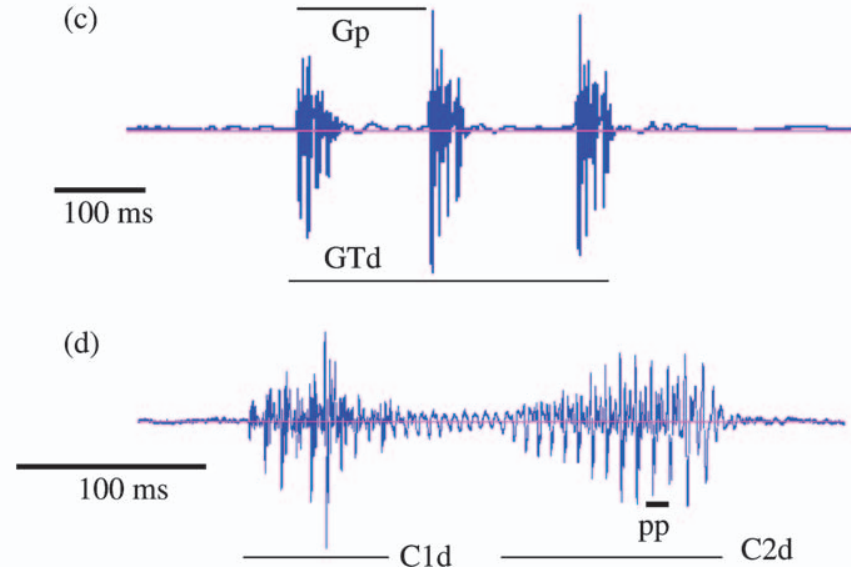

FIG. 1. Acoustic parameters measured in boatwhistles (a) oscillogram and (b) spectrogram, (c) grunt trains and (d) double croaks in Halobatrachus didactylus. TPd, tonal phase duration; H1, H2, H4, first, second and fourth harmonic in the boatwhistle tonal phase, respectively (H4 is the harmonic with most energy, i.e. the dominant frequency). GTd, grunt train duration; Gp, grunt period; Cld, first croak duration; C2d, second croak duration; pp, pulse period. Note that not all acoustic parameters are depicted. Time bars are given in (c) and (d).

means (Zar, 1984). Post hoc multiple group comparisons were conducted with Tukey tests. Boatwhistle, double croaks and grunt trains were analysed for several temporal and frequency features (see Table I and Fig. 1), measured from oscillograms and power spectra (Hamming window, filter bandwidth of $10 \mathrm{~Hz}$ ), respectively. Sound emission rate and acoustic parameters were correlated with 
TABLE I. Acoustic parameters measured in boatwhistles, double croaks and grunt trains emitted by Halobatrachus didactylus. The boatwhistle tonal phase is the larger portion of the boatwhistle situated between an initial and an ending grunt-like segment. $\mathrm{C} 1$ and $\mathrm{C} 2$ are the first and second croak of the double croak, respectively. $\mathrm{H} 2$ and $\mathrm{H} 4$ are the second and fourth frequency harmonics, which are the typical dominant frequencies in the boatwhistle

\begin{tabular}{|c|c|c|c|}
\hline Acoustic parameter & Boatwhistle & Double croak & Grunt train \\
\hline Duration (ms) & Total/tonal phase & Total $/ \mathrm{C}_{1}$ and $\mathrm{C}_{2}$ & Total \\
\hline Number of pulses & - & $\mathrm{C}_{1}$ and $\mathrm{C}_{2}$ & $\begin{array}{l}\text { Number of grunts } \\
\text { per bout }\end{array}$ \\
\hline Pulse period $(\mathrm{ms})^{1}$ & Tonal phase & $\mathrm{C}_{1}$ and $\mathrm{C}_{2}$ & Grunt period \\
\hline $\begin{array}{l}\text { Fundamental } \\
\text { frequency }(\mathrm{Hz})\end{array}$ & Tonal phase & $\mathrm{C}_{1}$ and $\mathrm{C}_{2}$ & Grunt bout \\
\hline $\begin{array}{l}\text { Dominant } \\
\text { frequency }(\mathrm{Hz})\end{array}$ & $\mathrm{H} 2$ and $\mathrm{H} 4$, tonal phase & $\mathrm{C}_{1}$ and $\mathrm{C}_{2}$ & Grunt bout \\
\hline
\end{tabular}

${ }^{1}$ Measured from peak to peak of consecutive pulses or, in the case of grunt bouts, of consecutive grunts.

temperature through Spearman rank correlations $\left(r_{\mathrm{s}}\right)$. Bonferroni corrections for multiple tests were applied to $P$ values. All statistical tests were performed with Statistica v. 7.1 for Windows (StatSoft, 2005).

The Lusitanian toadfish emitted sounds all year round (except in January 2002) but showed minimum levels of acoustic activity (near 0 sounds $\mathrm{min}^{-1}$ ) from October to January and February (Fig. 2). All sound types showed significant variation in the emission rate throughout the year (grunt trains: $F_{15,64}$, $P<0.001$; croaks: $F_{15,64}, P<0.001$; double croaks: $F_{15,64}, P<0.001$; boatwhistles: $\left.F_{15,64}, P<0 \cdot 001\right)$. Boatwhistle emission showed the most pronounced seasonal activity with no emission registered from October to March and significantly higher calling rates observed during the breeding season, from May to mid-July (Fig. 2; Tukey tests, $P<0 \cdot 05$ ). Boatwhistles were the most conspicuous sound type during the reproductive season (Fig. 2). Grunt trains and double croaks showed similar seasonal patterns, presenting minimum emission rates from October to January (grunt trains were not registered in December and January and double croaks were not registered in January), a slight increase in the pre-reproductive season (February to March), and an emission peak at the start of the mating season, in May (Fig. 2). Grunting levels in May were significantly higher than those observed for October to April and for late June onwards (Tukey tests, $P<0 \cdot 01$ ). Similarly, May double croak emission rates were significantly higher than that observed in 21 July 2001 to March 2002 and in 25 June 2002 to September 2002 (Tukey tests, $P<0 \cdot 05$ ). Croaks were emitted at low rates with slight variations throughout the year. The croak's emission rate was significantly higher in May when compared to the October to February emission levels (Fig. 2; Tukey tests, $P<0 \cdot 05$ ).

Seasonal patterns of acoustic emissions in male Lusitanian toadfish were significantly influenced by changes in water temperature. Sound production rate was positively correlated with this parameter (all sound types: $n=80, r_{\mathrm{s}}=$ 0.31 to $0.49, P<0.05$ ). Sound production rate and especially boatwhistles emission, however, dropped at the end of the breeding season (i.e. end of July) 

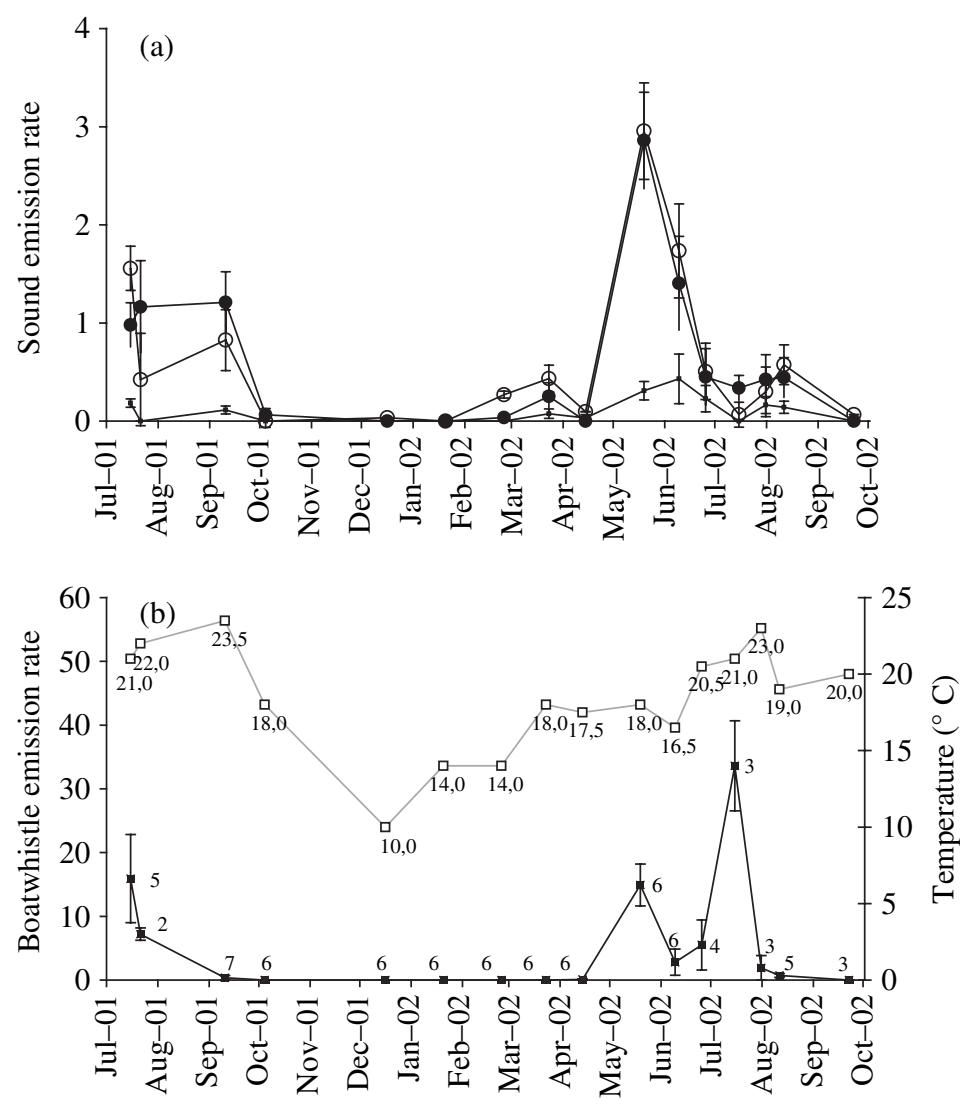

FIG. 2. Mean \pm S.E. (a) emission rates (number of sound $\min ^{-1}$ ) of double croaks $(\bullet)$, grunt trains $(\bigcirc)$, croaks $(\cdot)$ and (b) boatwhistles ( $\square$ ) in Halobatrachus didactylus. Water temperature ( $\square$ ) observed in the Tagus estuary (Montijo and Barreiro, Portugal) from July 2001 to September 2002 is given in (b). Numbers given in (b) correspond to the number of recording sessions (sample size).

despite the high water temperatures (Fig. 2). Water temperature also influenced acoustic features of sound emissions. Total boatwhistle duration $\left(n=100, r_{\mathrm{s}}=\right.$ $0 \cdot 46, P<0.001)$ and tonal phase (TP) duration $\left(n=100, r_{\mathrm{s}}=0.37, P<0.001\right)$ significantly increased with temperature. The TP pulse period decreased $(n=$ $\left.100, r_{\mathrm{s}}=-0.50, P<0.001\right)$ and the TP fundamental frequency increased $\left(n=100, r_{\mathrm{s}}=0.48, P<0.001\right)$ with rising temperature values. No significant correlation was found for TP dominant frequency (both $\mathrm{H}_{2}$ and $\mathrm{H}_{4}$ ) and temperature $\left(n=100, r_{\mathrm{s}}=0 \cdot 14\right.$ to $\left.0 \cdot 16, P>0.05\right)$. In grunt trains, grunt period decreased $\left(n=47, r_{\mathrm{s}}=-0.51, P<0.01\right)$ and the fundamental frequency increased $\left(n=47, r_{\mathrm{s}}=0.54, P<0.001\right)$ significantly with temperature. All other grunt features did not vary with temperature $\left(n=47, r_{\mathrm{s}}=-0.03\right.$ to $0.07, P>$ $0 \cdot 05)$. Total double croak and second croak durations $\left(n=38, r_{\mathrm{s}}=-0.62\right.$ to $-0.44, P<0.05)$, as well as the first and second croak pulse period $(n=38$, $r_{\mathrm{s}}=-0.76$ to $\left.-0.64, P<0.001\right)$, decreased with water temperature, but all other analysed features were not affected by temperature $\left(n=38, r_{\mathrm{s}}=-0 \cdot 20\right.$ to $0 \cdot 44$, $P>0 \cdot 05)$ 
This study has shown that the acoustic activity and repertoire size of the Lusitanian toadfish has a marked seasonal variation. The emission of boatwhistles was restricted to the breeding season, which is consistent with the suggestion that it is involved in mate attraction (dos Santos et al., 2000) as in other batrachoidids (Winn, 1972; Ibara et al., 1983; Brantley \& Bass, 1994). Grunts and double croaks were emitted all year round and showed a pronounced emission peak at the start of the breeding season. It is likely that these sound types are agonistic signals and may play a role in territorial establishment by nesting males. Other members of the Batrachoididae have shown a similar vocal behaviour (Amorim, 2006). Porichthys notatus Girard nesting males emit growls only at the start of the breeding season when males are occupying nest sites (Bass et al., 1999). Interestingly, growls have intermediate characteristics to the agonistic grunt and to the mating humming that are heard throughout the breeding season (Ibara et al., 1983; Brantley \& Bass, 1994). Agonistic grunts in Opsanus tau (L.) are produced by nesting males when conspecific males approach the nest, especially if the nesting males are guarding eggs or young (Gray \& Winn, 1961). In this species, grunts are emitted by both males and females outside the breeding season (Winn, 1967).

Sound production rate, regardless of sound type, increased with temperature. Activity in this species is strongly temperature dependent: spawning is only triggered with temperatures $>18^{\circ} \mathrm{C}$ and lethargy is induced by temperatures $<14-16{ }^{\circ} \mathrm{C}$ (J. L. Costa, pers. comm.). Consistently, some acoustic activity was present all year round, probably because water temperature only dropped below $14^{\circ} \mathrm{C}$ in January 2002. Likewise, when water temperature rose to $18^{\circ}$ $\mathrm{C}$ in March 2002, a slight increase in acoustic activity was observed, with few boatwhistles already registered in April $2002(0 \cdot 1 \pm 0.07$ boatwhistles $\left.\min ^{-1}\right)$. Moreover, the boatwhistle emission drop observed on 9 June 2002 was most likely caused by the sudden fall of water temperature (to $16.5{ }^{\circ} \mathrm{C}$ ) in that period. Temperature also influenced acoustic properties of boatwhistles, grunt trains and double croaks emitted by the Lusitanian toadfish. In general, sound duration and fundamental frequency increased, and pulse period decreased with rising water temperatures, which is consistent with other studies (Brantley \& Bass, 1994; Connaughton et al., 2000). This is probably related to temperature dependency of muscle contraction properties (Feher et al., 1998) and of pulse pattern generator circuits in the central nervous system (Bass \& Baker, 1991). Temperature, however, did not explain all the variability in the data in the present study (the highest $r_{\mathrm{s}}$ was $-0 \cdot 76$ ) suggesting that additional effects are involved. In $O$. tau, boatwhistle duration is not temperature dependent, although it varies seasonally (Fine, 1978), and in Opsanus beta (Goode \& Bean) the duration and other features of boatwhistles can also change in a daily cycle, unrelated to temperature (Thorson \& Fine, 2002). In H. didactylus, boatwhistles show clear individual differences (pers. obs.) and boatwhistle individuality can obscure significant temperature and season effects on acoustic parameters. Acoustic features and general acoustic activity observed in the Lusitanian toadfish must have also been influenced by seasonal androgen changes (Fine, 1978; Modesto \& Canário, 2003a, b). In batrachoidids and in other vocal fishes with pronounced seasonal acoustic activity, androgen variations associated with the breeding season cause sonic muscle hypertrophy and 
changes in fibre morphology that increase muscle contractile abilities and may affect sound properties (Brantley et al., 1993; Connaughton et al., 2002), although Johnson et al. (2000) found no seasonal pattern in the sonic neuromuscular system (sonic muscle mass and spinal sonic motor nucleus neurone soma size) in $O$. tau.

Vocal fish species that live in dark and turbid waters are difficult to see in their natural environment but can be monitored through passive acoustics (Luczkovich \& Sprague, 2001). Seasonal variation in the acoustic activity of the Lusitanian toadfish and other fishes can give information on their general activity, which typically increases around the reproductive season. In particular, detection of distinct seasonal emission patterns for different sound types, as found in the present study, may further elucidate the function of sound production in fish communication.

This study was supported by the pluriannual programme (UI\&D 331/94)/FCT, a grant POSI SFRH/BPD/14570/2003 of FCT (MCPA), a grant PRAXIS XXI/BD/ $11178 / 97$ of FCT (FA) and a grant from the Instituto Piaget.

\section{References}

Amorim, M. C. P. (2006). Diversity of sound production in fish. In Fish Communication (Ladich, F., Collin, S. P., Moller, P. \& Kapoor, B. G., eds), pp. 71-105. Enfield: Science Publishers.

Bass, A. H. \& Baker, R. (1991). Evolution of homologous vocal control traits. Brain, Behavior and Evolution 38, 240-254.

Bass, A. H. \& McKibben, J. R. (2003). Neural mechanisms and behaviors for acoustic communication in teleost fish. Progress in Neurobiology 69, 1-26. doi: 10.1016/ S0301-0082(03)00004-2

Bass, A. H., Bodnar, D. A. \& Marchaterre, M. A. (1999). Complementary explanations for existing phenotypes in an acoustic communication system. In Neural Mechanisms of Communication (Hauser, M. \& Konishi, M., eds), pp. 493-514. Cambridge: MIT Press.

Brantley, R. K. \& Bass, A. H. (1994). Alternative male spawning tactics and acoustic signals in the plainfin midshipman fish, Porichthys notatus (Teleostei, Batrachoididae). Ethology 96, 213-232.

Brantley, R. K., Marchaterre, M. A. \& Bass, A. H. (1993). Androgen effects on vocal muscle structure in a teleost fish with inter- and intra-sexual dimorphism. Journal of Morphology 216, 305-318.

Connaughton, M. A., Taylor, M. H. \& Fine, M. L. (2000). Effects of fish size and temperature on weakfish disturbance calls: implications for the mechanism of sound generation. The Journal of Experimental Biology 203, 1503-1512.

Connaughton, M. A., Fine, M. L. \& Taylor, M. H. (2002). Weakfish sonic muscle: influence of size, temperature and season. The Journal of Experimental Biology 205, 2183-2188.

Feher, J. J., Waybright, T. D. \& Fine, M. L. (1998). Comparison of sarcoplasmic reticulum capabilities in toadfish (Opsanus tau) sonic muscle and rat fast twitch muscle. Journal of Muscle Research and Cell Motility 19, 661-674. doi: 10.1023/ A:1005333215172

Fine, M. L. (1978). Seasonal and geographical variation of the mating call of the oyster toadfish Opsanus tau L. Oecologia 36, 45-57.

Fine, M. L., Malloy, K. L., King, C. B., Mitchell, S. L. \& Cameron, T. M. (2001). Movement and sound generation by the toadfish swimbladder. Journal of Comparative Physiology A 187, 371-379. doi: 10.1007/s003590100209 
Fish, J. F. (1972). The effect of sound playback on the toadfish. In Behavior of Marine Animals, Vol. 2 (Winn, H. E. \& Olla, B., eds), pp. 386-434. New York: Plenum Press.

Gray, G. A. \& Winn, H. E. (1961). Reproductive ecology and sound production of the toadfish Opsanus tau. Ecology 28, 274-282.

Ibara, R. M., Penny, L. T., Ebeling, A. W., van Dykhuizen, G. \& Caillet, G. (1983). The mating call of the plainfin midshipman, Porichthys notatus. In Predators and Prey (Noakes, D. G. L., Lindquist, D. G., Helfman, G. S. \& Ward, J. A., eds), pp. 205212. The Hague: Junk Press.

Johnson, M. S., Waybright, T. D., Matt, D. W., Feher, J. J. \& Fine, M. L. (2000). Absence of a seasonal cycle in the sonic neuromuscular system of the oyster toadfish. Journal of Fish Biology 56, 211-215. doi: 10.1111/j.10958649.2000.tb02097.x

Luczkovich, J. \& Sprague, M. W. (2001). Using passive acoustics to monitor spawning of fishes in the drum family - Sciaenidae. The Journal of the Acoustical Society of America 110, 2639.

Modesto, T. \& Canário, A. V. M. (2003a). Morphometric changes and sex steroid levels during the annual reproductive cycle of the Lusitanian toadfish, Halobatrachus didactylus. General and Comparative Endocrinology 131, 220-231. doi: 10.1016/ S0016-6480(03)00027-3

Modesto, T. \& Canário, A. V. M. (2003b). Hormonal control of swimbladder sonic muscle dimorphism in the Lusitanian toadfish Halobatrachus didactylus. The Journal of Experimental Biology 206, 3467-3477. doi: 10.1242/jeb.00581

dos Santos, M., Modesto, T., Matos, R. J., Grober, M. S., Oliveira, R. F. \& Canario, A. (2000). Sound production by the Lusitanian toadfish, Halobatrachus didactylus. Bioacoustics 10, 309-321.

Statsoft (2005). Statistica v. 7.1 for Windows. Tulsa, OK: Statsoft, Inc.

Thorson, R. F. \& Fine, M. L. (2002). Crepuscular changes in emission rate and parameters of the boatwhistle advertisement call of the gulf toadfish, Opsanus beta. Environmental Biology of Fishes 63, 321-331. doi: 10.1023/A:1014334425821

Winn, H. E. (1967). Vocal facilitation and the biological significance of toadfish sounds. In Marine Bio-Acoustics, Vol. 2 (Tavolga, W. N., ed.), pp. 283-304. Oxford: Pergamon Press.

Winn, H. E. (1972). Acoustic discrimination by the toadfish with comments on signal systems. In Behavior of Marine Animals, Vol. 2 (Winn, H. E. \& Olla, B., eds), pp. 361-385. New York: Plenum Press.

Zar, J. H. (1984). Biostatistical Analysis, 2nd edn. New Jersey: Prentice Hall. 